Part of Journal of Research of the National Bureau of Standards, Volume 28, June 1942

\title{
EFFECT OF ALTITUDE ON KNOCK RATING IN CFR ENGINES
}

\author{
By Donald B. Brooks
}

ABSTRACT

Knock ratings made at altitude have shown systematic differences from ratings made at sea level, on some fuel types. Altitude-chamber tests showed that complete agreement could be obtained if tests were made at uniform knock intensity, and that uniform knock intensity was obtained when the cylinder clearance volume was reduced in linear relation to air pressure. From these tests, equations are developed to relate clearance volume for standard knock intensity to air pressure and to octane number for the ASTM Motor and the CFR Research Methods of knock rating. Equations are also developed to relate octane-number requirement to air pressure, and these are shown to agree with road-test data.

CONTENTS

Page

I. Introduction .

II. Description of CFR engine

III. Test equipment _._.

IV. Preliminary altitude-chamber tests_.

V. Final altitude-chamber tests

1. Test procedure

2. Test results

VI. Guide curves_........

VII. Effect of altitude on octane-number requirement $\ldots \ldots \ldots 27$

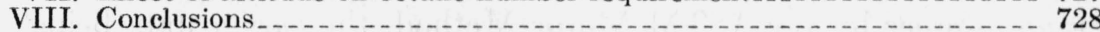

IX. References _...

\section{INTRODUCTION}

Since the knock rating of motor gasolines was placed on a uniform basis by the adoption in 1933 of the ASTM Motor Method which was developed by the Cooperative Fuel Research Committee, ratings made by laboratories located at higher altitudes frequently have failed to agree with ratings made by other laboratories operating near sea level. While the magnitudes of the discrepancies varied with fuel type, they were generally systematic with respect to altitude, and often too large to be ascribed to known sources of accidental errors.

Cooperative field tests definitely correlated the effect with altitude. In 1937, Holaday and Moore reported $[1]^{1}$ an investigation in which the effects of altitude were obtained by reducing the intake and exhaust pressures of a CFR-ASTM Motor Method engine. As the result of this investigation, a series of larger venturis was prescribed for use at different altitudes in place of the venturi used at sea level. These recommendations were based on the thesis of maintaining constant compression pressure at all altitudes, although the experimental work of these investigators showed that this did not result in maintaining constant knock intensity. Some improvement in results followed the adoption of the recommendations of Holaday and Moore.

\footnotetext{
1 Figures in brackets indicate the literature references at the end of this paper.
} 
Adoption of the 1939 CFR Research Method by the Cooperative Fuel Research Committee again raised the problem of modifications required for knock rating at altitude. A program of field tests was carried on in 1940 in which coincident change of venturi size and spark advance was tried as a means of compensation for reduced air pressure. The ratings so obtained showed an undesirably large spread for some fuels.

Early in 1941, the National Bureau of Standards was asked by the Altitude Procedure Group of the CFR Motor Fuels Division to assist in determining appropriate conditions for knock rating by the ASTM Motor and the CFR Research Methods at altitudes up to 7,000 ft. by cooperative tests in one of the Bureau's altitude chambers, skilled technicians and additional cylinder assemblies being made available by the participating organizations.

Preliminary tests were carried out on a CFR engine in April 1941. Altitude procedures based thereon were subjected to field tests, and were found to be substantially correct. An additional assignment was then given to this project, this being to determine the variation of compression ratio with octane number which would be required to maintain standard knock intensity at all octane numbers. Heretofore this had been defined at only two levels of octane number. The curve of compression ratio or its equivalent, micrometer setting, for standard knock intensity versus octane number, is known as a "guide curve." This assignment was carried out in conjunction with the final tests in the altitude chamber, three CFR-engine cylinder assemblies being used in this work. The procedures and recommendations resulting from this work were subjected to field tests in December 1941. Additional field tests were made late in January 1942 to determine the best compression ratio for knock rating in the region of 100 octane number by the ASTM Motor Method, the earlier data being unsatisfactory at this level. The final recommendations were approved February 6 by the CFR Committee.

\section{DESCRIPTION OF CFR ENGINE}

The engine $[2,3,4,5,6]$ currently approved for the knock rating of motor gasolines has been designed and built to the specifications of the Cooperative Fuel Research Committee. It is a single-cylinder engine belt-connected to a synchronous motor-generator, which maintains engine speed constant at all times. A mechanism for raising or lowering the cylinder relative to the crankcase permits continuous variation of the compression ratio. The height of the cylinder, and inferentially the cylinder clearance volume and the compression ratio, is measured by a micrometer suitably located and graduated in thousandths of an inch. The micrometer is so adjusted that a reading of $0.000 \mathrm{in}$. corresponds to a compression ratio of 10.0 , and a reading of $1.000 \mathrm{in}$. to a compression ratio of 4.0. Compression ratio, $R$, is determined by cylinder clearance volume and is related to micrometer setting, $M$, according to the equation

$$
R=\frac{M+5}{M+0.5} .
$$

When operating by ASTM Motor Method [7], the engine speed is $900 \mathrm{rpm}$ and the intake-mixture temperature is $300^{\circ} \mathrm{F}$. The spark 
advance is automatically varied in accordance with the compression ratio. In sea-level operation, a 9/16-in. venturi is used in the carburetor, and a throttle plate (thin-plate rectangular orifice) constricts the passage from carburetor to engine. The CFR Research Method requires an engine speed of $600 \mathrm{rpm}$, an intake air temperature of $125^{\circ} \mathrm{F}$, and fixed spark advance. In sea-level operation, a 9/16-in. venturi is used, without the throttle plate.

When operating by either method, the temperature of the engine coolant is maintained constant within $1^{\circ} \mathrm{F}$ and is held within the limits $209^{\circ}$ to $215^{\circ} \mathrm{F}$. The humidity of the intake air is not allowed to exceed 50 grains of moisture per pound of dry air, and is customarily regulated by passing the intake air through cracked ice in a tower so designed that the output air humidity is maintained at 27 grains of moisture per pound of dry air at standard barometric pressure.

The intensity of knock is indicated on a "knockmeter", which is actuated by a "bouncing-pin." The latter consists of a steel pin resting on a steel diaphragm flush with the upper combustion chamber surface of the engine cylinder. The impact of knock causes the pin to "bounce" and close a pair of contacts. The current flowing through the contacts is indicated by the knockmeter, a thermocouple ammeter sufficiently damped so that no fluctuation in the indicating needle occurs between successive contacts. Suitable adjustments are provided to limit pin travel and chatter.

As the knock ratings of some types of fuels vary with knock intensity, it is necessary to define and maintain a "standard knock intensity." In making a knock rating, the bouncing pin is first "standardized," that is, the adjustments of the pin are varied until it causes the same knockmeter reading when operating at appropriate compression ratios at each of the two standard levels of octane number. At an atmospheric pressure of $29.92 \mathrm{in.} \mathrm{Hg}$, standard knock intensity by the ASTM Motor Method has been defined as that produced by use of a standard fuel of 65 octane number at 5.3 compression ratio and 90 octane number at 7.1, whereas by the CFR Research Method, the corresponding values were 70 octane number at 5.75 compression ratio and 90 octane number at 6.7. The compression ratio is then adjusted so that the test fuel gives a knock of standard intensity, as indicated by the knockmeter. By direct comparison, or by the use of calibrated reference fuels, the composition of that blend of 2,2,4trimethylpentane ("isooctane") and normal heptane which gives a knockmeter reading equal to that of the test fuel is ascertained. The percentage of isooctane in such blend is the octane number of the fuel.

\section{TEST EQUIPMENT}

A standard CFR unit with ice-tower humidity control was installed in a National Bureau of Standards altitude chamber [8]. The condenser of the engine was sealed and was vented outside the chamber, to maintain constant coolant temperature at all altitudes. The engine inducted and exhausted at chamber pressure. Pressure in the chamber was determined by a mercury manometer and a calibrated barometer, and was maintained constant within 0.01 in. $\mathrm{Hg}$ during each test. 
With each cylinder assembly, the micrometer was adjusted by measuring the clearance volume with one side of the engine base raised one-half inch so that the bouncing-pin hole was at the higher side of the head. Each operator was asked to adjust his bouncing pin by his usual method, but to endeavor to obtain a setting which would give the same knockmeter reading when the engine was adjusted to give standard knock intensity at each of the two specified levels of octane number.

\section{PRELIMINARY ALTITUDE-CHAMBER TESTS}

In the first series of altitude-chamber tests, similar programs were carried out for the ASTM Motor and CFR Research Methods. The general objectives were to determine for each modification of the induction system (venturi size, throttle plate) at a series of altitudes up to $8,000 \mathrm{ft}$ (a) the compression ratio for constant absolute compression pressure, (b) the compression ratio for standard knock intensity at the two levels of octane number, and (c) the compression ratio at which the rating of a sensitive fuel, known as $X-1$, was the same as that found for it at sea level.

The general procedure at each altitude was to make measurements of the variable in question at a series of compression ratios. The resulting data were plotted, and the compression ratio was found at which the variable had the same value as it had at sea level.

The results of these tests showed:

1. Ratings made at constant knock intensity were independent of air pressure.

2. Constant knock intensity was not obtained at constant absolute compression pressure.

3. Compression ratio for constant knock intensity was a curvilinear function of air pressure.

4. The micrometer setting for constant knock intensity was a linear function of air pressure, the derivative of this function being the same at both levels of octane number, although it was different for the two test methods.

5. No advantage resulted from the use of more than three sizes of venturi for the ASTM Motor Method, or one size for the CFR Research Method.

To verify these findings in service, field tests were run in which 9 fuels were rated by over 20 laboratories, two-thirds of these being located near sea level and the remainder at higher altitudes up to $6,600 \mathrm{ft}$. The resulting ratings showed no trend with altitude, and the average of the values obtained by the altitude laboratories was within 0.1 octane unit of that found by the sea-level group. The average of the standard deviations of the results reported by the altitude laboratories was one-fourth larger than the sea-level average, which difference might be expected [9] in view of the generally greater experience of the personnel of the sea-level group. 


\section{FINAL ALTITUDE-CHAMBER TESTS}

\section{TEST PROCEDURE}

To make certain that the results were not biased by the idiosyncrasies of any particular engine, three additional cylinder assemblies were used in these tests. The procedure with each cylinder assembly consisted in standardizing the bouncing-pin setting at sea level, then running guide curves at selected altitudes, and altitude curves (micrometer setting for standard knock intensity) with fuels of selected octane numbers.

ASTM Motor Method tests were made in all cases by standardizing the pin with the $\% 16$-in. venturi and throttle plate. Guide and altitude curves were determined with the $9 / 16$-in. venturi with throttle plate, and with the $9 / 16^{-}, 19 / 32^{-}$, and $3 / 4^{-i n}$. venturis without throttle plate. CFR Research Method tests were made only with the $9 / 16$-in. venturi, the earlier tests having shown that larger venturis did not increase the volumetric efficiency appreciably, and therefore would not alter the knock intensity.

On the first cylinder assembly, guide curves were run with the $9 / 16^{-}, 19 / 32^{-}$, and $3 / 4^{-i n}$. venturis at sea level, and at pressures of $28,26,24$, and $22 \mathrm{in.} \mathrm{Hg}$. On subsequent assemblies, curves were determined only at $28 \mathrm{in} . \mathrm{Hg}$, this point being selected in preference to operating at sea level with uncontrolled air pressure. Altitude curves were generally determined from sea level to $22 \mathrm{in}$. $\mathrm{Hg}$, but were extended below this pressure in certain instances, being carried to an equivalent altitude of 20,000 ft. in one case. Knockmeter drift was determined by repeating the first test point at the end of the test, and due correction of intermediate tests was made.

Guide curves were determined by finding the micrometer setting for standard knock intensity for reference fuels of $40,50,60,65$ (ASTM Motor Method only), 70, 80, 90, 95, and 100 octane number.

\section{TEST RESULTS}

Data taken to determine the ASTM Motor Method guide curve for each venturi are listed in table 1 . The columns give in order the cylinder assembly, the venturi size, the barometric pressure at which the test was run, and the micrometer settings found to give standard knock intensity with each blend of secondary reference fuels. The last column gives the rating of reference fuel $X-1$, as interpolated from the micrometer setting found to give standard knock intensity with this fuel. Allowing for the reduced accuracy of this indirect but rapid method of estimating the rating of $X-1$, no significant differences in the ratings of this sensitive reference fuel were found with different venturis or at different altitudes.

Table 1 illustrates the necessity for readjustment of the bouncingpin above 90 octane number. Except where noted, the pin was not readjusted in making these runs. In several cases the micrometer setting found at 100 octane number is as high as or higher than that at 95 octane number. Careful study of pin behavior in this range led to the belief that more than one pin setting may be required to cover the range 90 to 100 octane number. 
TAble 1.-Guide-curve data-ASTM Motor Method

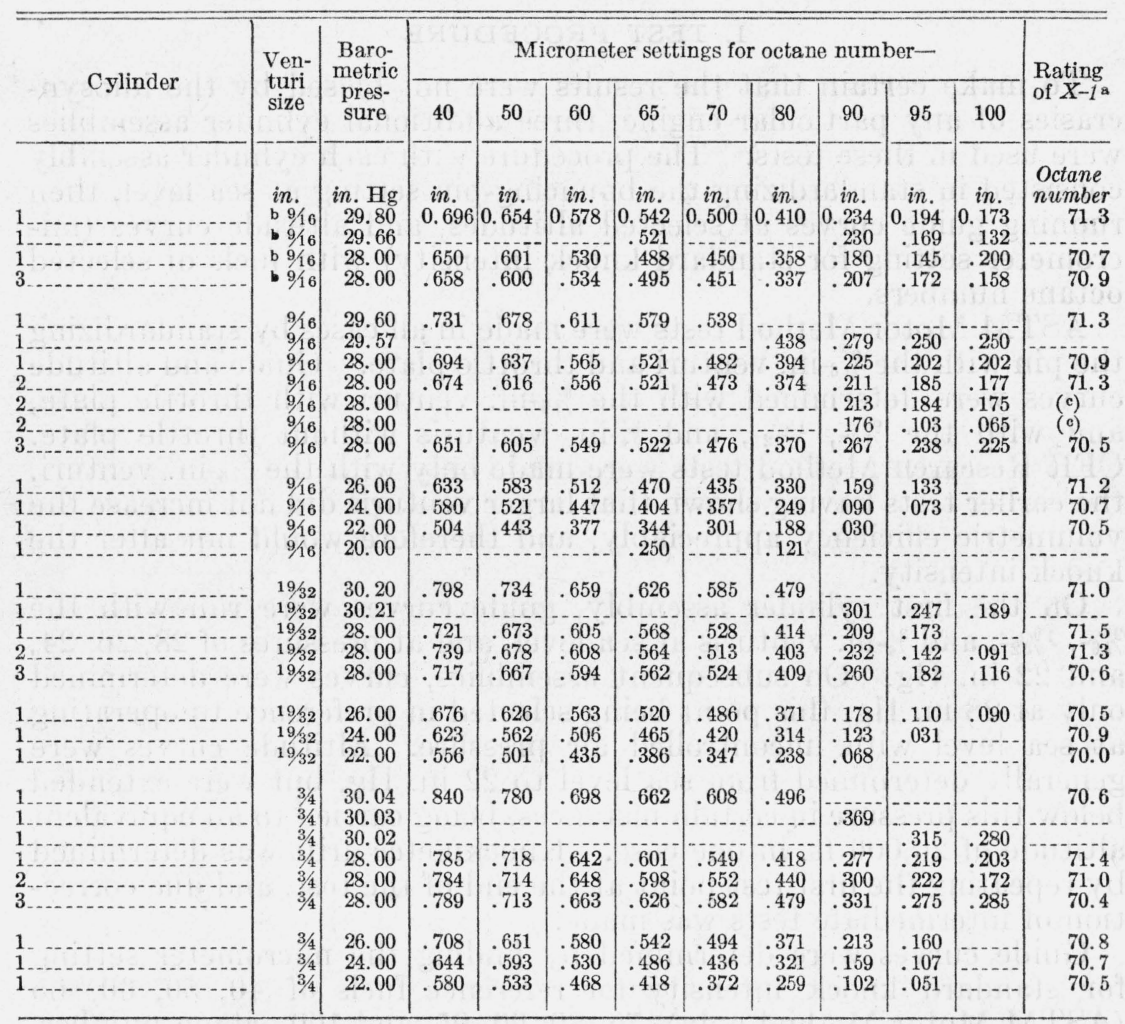

a Interpolated rating.

b With throttle plate.

- Pin reset.

TABLE 2.-Altitude data-ASTM Motor Method

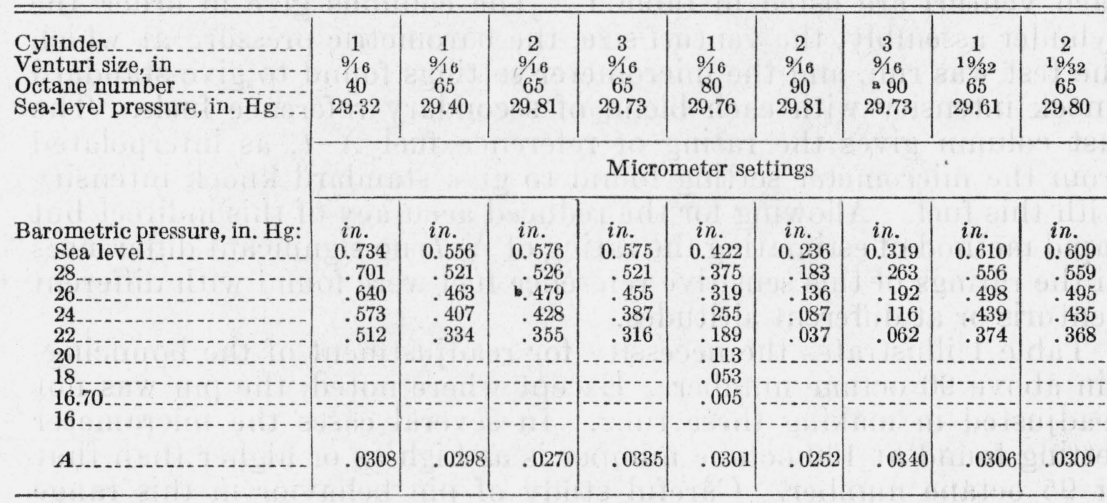

See footnotes at end of table. 
TABLE 2.-Altitude data-ASTM Motor Method-Continued

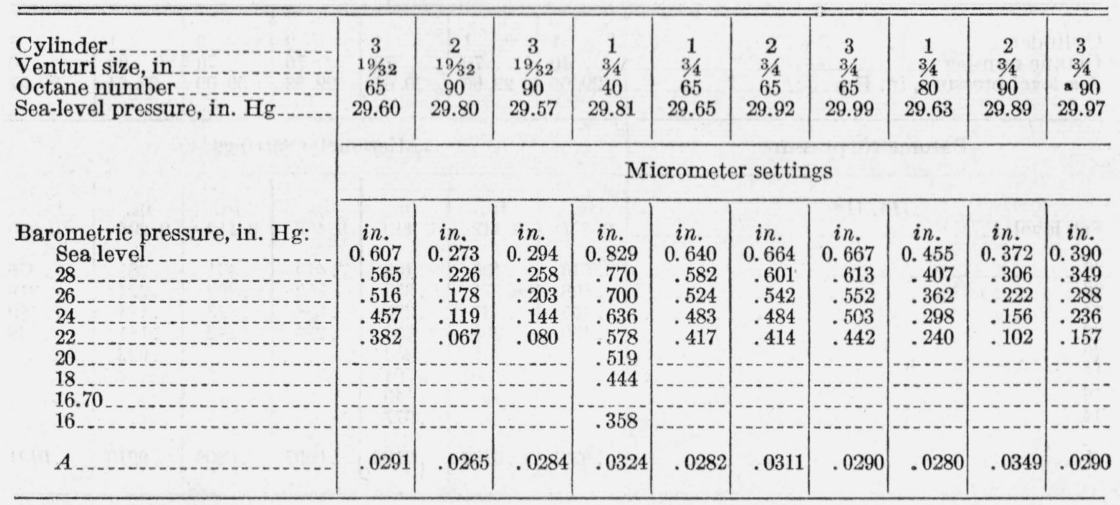

ain setting faulty.

b Barometric pressure, 25.96 in. Hg by error

Altitude data obtained by the ASTM Motor Method are listed in table 2. The constant $A$ listed at the bottom of the table is the change of micrometer setting for constant knock intensity in inches per 1 -in. $\mathrm{Hg}$ change of air pressure. These data indicate a linear relation between micrometer setting and air pressure within experimental error for air pressures above $20 \mathrm{in.} \mathrm{Hg}$. The average value of $A$ obtained from these data and from the data of table 1 is 0.0300 . From relatively few data obtained in the earlier altitude-chamber tests, the value 0.0341 was found.

Tables 3 and 4 give the guide curve and altitude data for the CFR Research Method. The value of $A$ for this method is found to be 0.0200 , as compared with the value 0.0207 found earlier. As in the case of the ASTM Motor Method, the data are linear above 20 in. $\mathrm{Hg}$ within experimental error.

TABLE 3.-Guide-curve data-CFR Research Method

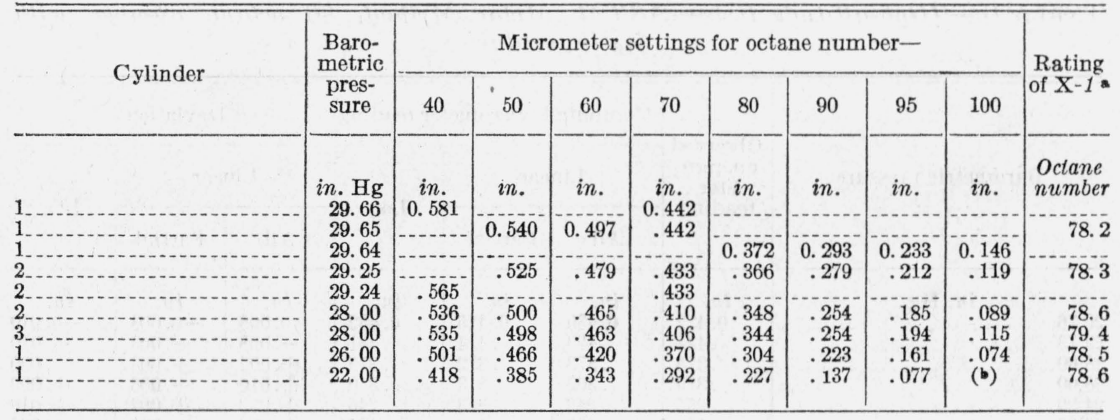

Interpolated rating.

b Slightly below 0.000 . 
TABLE 4.-Altitude data-CFR Research Method

\begin{tabular}{|c|c|c|c|c|c|c|c|}
\hline $\begin{array}{l}\text { Cylinder } \\
\text { Octane number } \\
\text { Sea-level pressure, in. } \mathrm{Hg}\end{array}$ & $\begin{array}{r}1 \\
40 \\
29.65\end{array}$ & $\begin{array}{r}1 \\
70 \\
29.66\end{array}$ & $\begin{array}{r}1 \\
70 \\
61\end{array}$ & $\begin{array}{r}2 \\
70 \\
29 . \\
53\end{array}$ & $\begin{array}{r}3 \\
70 \\
30.00\end{array}$ & $\begin{array}{r}1 \\
90 \\
29.64\end{array}$ & $\begin{array}{r}3 \\
90 \\
29.97\end{array}$ \\
\hline Barometric pressure & \multicolumn{7}{|c|}{ Micrometer settings } \\
\hline Sea level $\quad$ in. $\mathrm{Hg}$ & $\stackrel{i n .}{0.577}$ & $\stackrel{i n .}{0.442}$ & $\stackrel{i n .}{0.440}$ & $\stackrel{i n .}{0.439}$ & in. & in. & in. \\
\hline $28{ }^{2}{ }^{2}{ }^{2}$ & 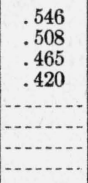 & $\begin{array}{l}.405 \\
.371 \\
.337 \\
.298 \\
.251 \\
- \\
- \\
-\end{array}$ & $\begin{array}{l}409 \\
.373 \\
.335 \\
.293 \\
.252 \\
.204 \\
.146 \\
.077\end{array}$ & 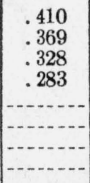 & $\begin{array}{c}.401 \\
.362 \\
.323 \\
.282 \\
-0 \\
\end{array}$ & $\begin{array}{l}.265 \\
.221 \\
.184 \\
.141 \\
.092 \\
\\
\end{array}$ & $\begin{array}{r}.256 \\
.218 \\
.180 \\
.138 \\
\\
\\
\end{array}$ \\
\hline A.... & .0205 & .0192 & .0195 & .0207 & .0206 & .0210 & .0191 \\
\hline
\end{tabular}

TABLE 5.-High-altitude tests-ASTM Motor Method, 40 octane number with 3\%4-in. venturi

\begin{tabular}{|c|c|c|c|c|c|c|c|}
\hline \multirow{3}{*}{ Barometric pressure } & \multirow{3}{*}{$\begin{array}{c}\text { Observed } \\
\text { microm- } \\
\text { eter read- } \\
\text { ing }\end{array}$} & \multicolumn{3}{|c|}{ Computed micrometer reading } & \multicolumn{3}{|c|}{ Deviations } \\
\hline & & \multicolumn{2}{|c|}{ Linear } & \multirow{2}{*}{$\log$} & \multicolumn{2}{|c|}{ Linear } & \multirow{2}{*}{$\log$} \\
\hline & & All & Partial & & All & Partial & \\
\hline $\begin{array}{l}\text { in. } \mathrm{Hg} \\
29.81 \\
29.77 \\
28.00 \\
26.00 \\
24.00 \\
20.00 \\
18.00 \\
16.00\end{array}$ & $\begin{array}{r}\text { in. } \\
0.829 \\
.827 \\
.770 \\
.700 \\
.636 \\
.578 \\
.519 \\
.444 \\
.358\end{array}$ & $\begin{array}{l}\text { in. } \\
0.830 \\
.829 \\
.770 \\
.704 \\
.638 \\
.572 \\
.506 \\
.439 \\
.373\end{array}$ & $\begin{array}{r}\text { in. } \\
0.828 \\
.826 \\
.769 \\
.704 \\
.639 \\
.574 \\
\\
\end{array}$ & $\begin{array}{l}\text { in. } \\
0.826 \\
.825 \\
.770 \\
.707 \\
.643 \\
.577 \\
.509 \\
.438 \\
.365\end{array}$ & $\begin{array}{l}\text { in. } \\
-0.001 \\
-.002 \\
.000 \\
-.004 \\
-.002 \\
+.006 \\
+.013 \\
+.005 \\
-.015\end{array}$ & $\begin{array}{r}\text { in. } \\
+0.001 \\
+.001 \\
+.001 \\
-.004 \\
-.003 \\
+.004 \\
\end{array}$ & $\begin{array}{r}\text { in. } \\
+0.003 \\
+.002 \\
.000 \\
-.007 \\
-.007 \\
+.001 \\
+.010 \\
+.006 \\
-.007\end{array}$ \\
\hline Standard deviation.... & & & & & 0.007 & 0.003 & 0.006 \\
\hline
\end{tabular}

TABLE 6.-High-altitude tests-ASTM Motor Method, 80 octane number with $9 / 16$-in. venturi

\begin{tabular}{|c|c|c|c|c|c|c|c|}
\hline \multirow{3}{*}{ Barometric pressure } & \multirow{3}{*}{$\begin{array}{l}\text { Observed } \\
\text { microm- } \\
\text { eter } \\
\text { reading }\end{array}$} & \multicolumn{3}{|c|}{ Computed micrometer reading } & \multicolumn{3}{|c|}{ Deviations } \\
\hline & & \multicolumn{2}{|c|}{ Linear } & \multirow{2}{*}{$\log$} & \multicolumn{2}{|c|}{ Linear } & \multirow{2}{*}{$\log$} \\
\hline & & All & Partial & & All & Partial & \\
\hline $\begin{array}{l}\text { in. } \mathrm{Hg} \\
29.76 \\
29.73 \\
26.00 \\
24.00 \\
22.00 \\
20.00\end{array}$ & $\begin{array}{l}\text { in. } \\
0.422 \\
.421 \\
.375 \\
.319 \\
.255 \\
.189 \\
.113 \\
.053 \\
.005\end{array}$ & $\begin{array}{l}\text { in. } \\
0.430 \\
.429 \\
.373 \\
.309 \\
.246 \\
.182 \\
.118 \\
.054 \\
.012\end{array}$ & $\begin{array}{r}\text { in. } \\
0.425 \\
.424 \\
.372 \\
.313 \\
.253 \\
194 \\
- \\
\hdashline\end{array}$ & $\begin{array}{l}\text { in. } \\
0.432 \\
.431 \\
.375 \\
.310 \\
.245 \\
.181 \\
.116 \\
.052 \\
.011\end{array}$ & $\begin{array}{l}\text { in. } \\
-0.008 \\
-.008 \\
+.002 \\
+.010 \\
+.009 \\
+.007 \\
-.005 \\
-.001 \\
-.007\end{array}$ & $\begin{array}{l}\text { in. } \\
-0.003 \\
-.003 \\
+.003 \\
+.006 \\
+.002 \\
-.005 \\
\end{array}$ & $\begin{array}{r}\text { in. } \\
-0.010 \\
-.010 \\
.000 \\
+.009 \\
+.010 \\
+.008 \\
+.003 \\
+.001 \\
-.006\end{array}$ \\
\hline \multicolumn{5}{|c|}{ Standard deviation } & 0.007 & 0.004 & 0.007 \\
\hline
\end{tabular}


TABLE 7.-High-altitude tests-CFR Research Method, 70 octane number

\begin{tabular}{|c|c|c|c|c|c|c|c|}
\hline \multirow{3}{*}{ Barometric pressure } & \multirow{3}{*}{$\begin{array}{l}\text { Observed } \\
\text { microm- } \\
\text { eter } \\
\text { reading }\end{array}$} & \multicolumn{3}{|c|}{ Computed micrometer reading } & \multicolumn{3}{|c|}{ Deviations } \\
\hline & & \multicolumn{2}{|c|}{ Linear } & \multirow{2}{*}{$\log$} & \multicolumn{2}{|c|}{ Linear } & \multirow{2}{*}{$\log$} \\
\hline & & All & Partial & & All & Partial & \\
\hline $\begin{array}{l}\text { in. } \mathrm{Hg} \\
29.61 \\
29.57 \\
26.000 \\
24.00 \\
22.00 \\
18.00\end{array}$ & $\begin{array}{l}\text { in. } \\
0.440 \\
.440 \\
.409 \\
.373 \\
.335 \\
.293 \\
.252 \\
.204 \\
.146 \\
.077\end{array}$ & $\begin{array}{l}\text { in. } \\
0.450 \\
.449 \\
.414 \\
.370 \\
.325 \\
.281 \\
.237 \\
.192 \\
.148 \\
.103\end{array}$ & $\begin{array}{r}\text { in. } \\
0.441 \\
.440 \\
.410 \\
.371 \\
.333 \\
.295 \\
\\
\end{array}$ & $\begin{array}{l}\text { in. } \\
0.438 \\
.438 \\
.411 \\
.375 \\
.337 \\
.295 \\
.250 \\
.201 \\
.144 \\
.079\end{array}$ & $\begin{array}{r}\text { in. } \\
-0.010 \\
-.009 \\
-.005 \\
+.003 \\
+.010 \\
+.012 \\
+.015 \\
+.012 \\
-.002 \\
-.026\end{array}$ & $\begin{array}{r}\text { in. } \\
-0.001 \\
.000 \\
-.001 \\
+.002 \\
+.002 \\
-.002 \\
\end{array}$ & $\begin{array}{l}\text { in. } \\
+0.002 \\
+.002 \\
-.002 \\
-.002 \\
-.002 \\
-.002 \\
+.002 \\
+.003 \\
+.002 \\
-.002\end{array}$ \\
\hline \multicolumn{5}{|c|}{ Standard deviation. } & 0.012 & 0.0015 & 0.0021 \\
\hline
\end{tabular}

The data obtained at air pressures below $20 \mathrm{in} . \mathrm{Hg}$ indicate that the relation between micrometer setting and altitude is more nearly logarithmic, as found in an analysis of the earlier data [10]. This is shown in figures 1 and 2 , and tables 5, 6, and 7, in which the observed data and values calculated from linear and logarithmic equations are shown. The logarithmic equations used for the ASTM Method tests are of the form

where

$$
\log (M+0.5)=\alpha \log p+\beta,
$$

$$
\begin{aligned}
\mathrm{M} & =\text { micrometer setting, in., } \\
p & =\text { barometric pressure, in. } \mathrm{Hg}, \\
\alpha, \beta & =\text { empirical constants. }
\end{aligned}
$$

That used for the CFR Research Method data plotted in figure 2, has been modified by replacing $p$ by $(p-a)$, where $a$ is also an empirical constant. This modification results in a much better fit, as can be seen by the deviations, table 7 . The value found for $a$ is $7.7 \mathrm{in} . \mathrm{Hg}$, and the equation suggests that this is a lower limit for detonation of the type prevailing at normal pressures, as this excellently fitting equation would require a micrometer setting of $-0.5 \mathrm{in}$. (infinite compression ratio) at $7.7 \mathrm{in} . \mathrm{Hg}$ air pressure for standard knock intensity.

In figure 1 , the values for the $3 / 4$-in. venturi at 40 octane number and the $\% 16$-in. venturi at 80 octane number have been plotted on offset scales, to show by juxtaposition the great similarity of behavior at a maximum difference in initial micrometer setting.

In tables 8 and 9, the guide-curve data for the ASTM Motor and the CFR Research Methods have been corrected to standard sealevel pressure (29.92 in. $\mathrm{Hg}$ ), by use of the constants evaluated above. A study of these tables shows that there is no change of shape of the guide curve at altitude; it is simply shifted uniformly to lower micrometer values. This amounts to saying that the constant $A$ is the same for all octane numbers; this fact has been directly verified by analysis also. 


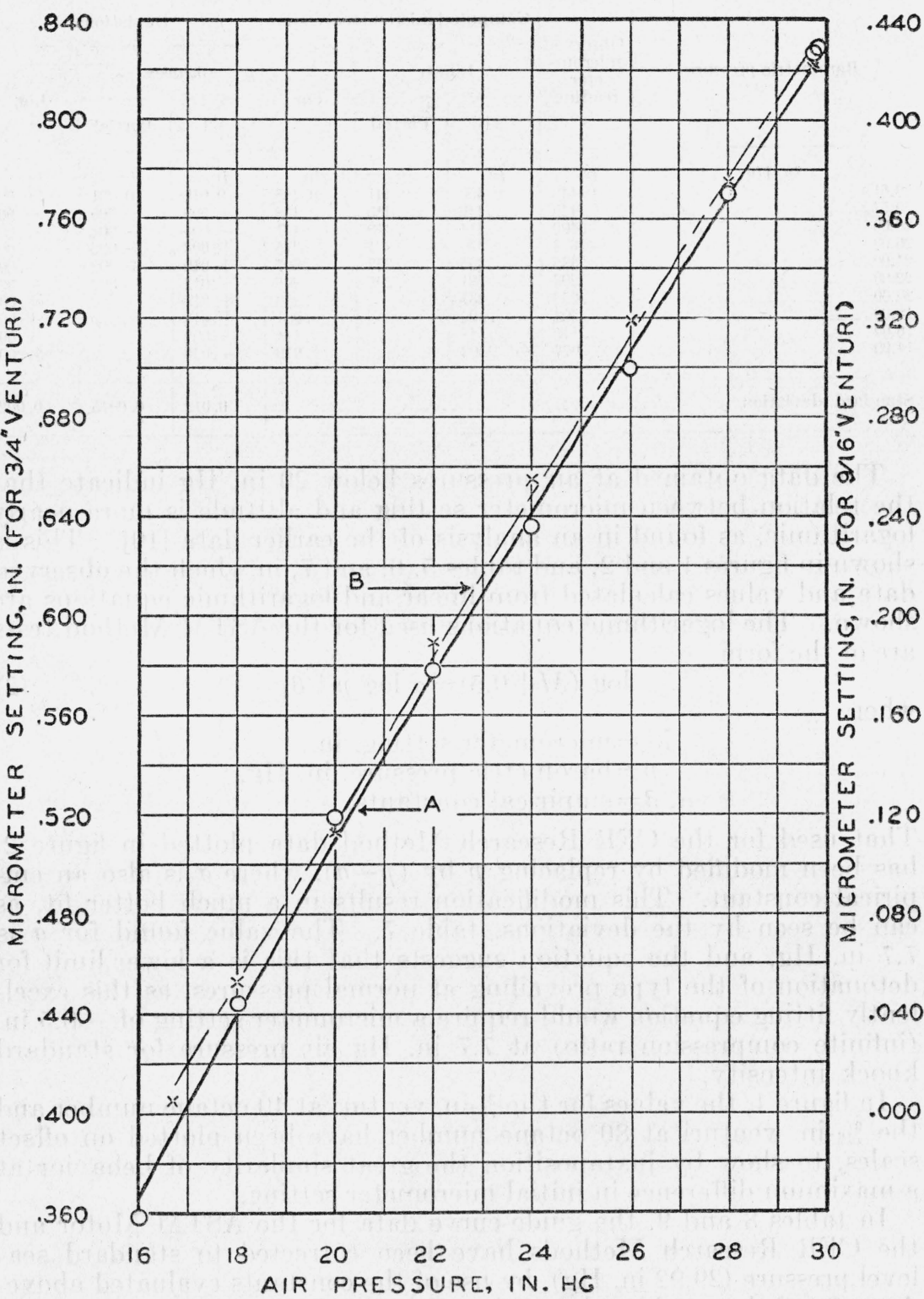

FIGURE 1.-Micrometer settings for standard knock intensity by ASTM Motor Method.

The circles and solid-line curve $A$, represent data taken with the 3/4-in. venturi, using 40-octane-number fuel, and the crosses and broken-line curve, $B$, those with the $\% / 6$-in. venturi, using 80 -octane-number fuel. The scales of micrometer setting are offset to bring the two curves into juxtaposition, to show the similarity of behavior. 


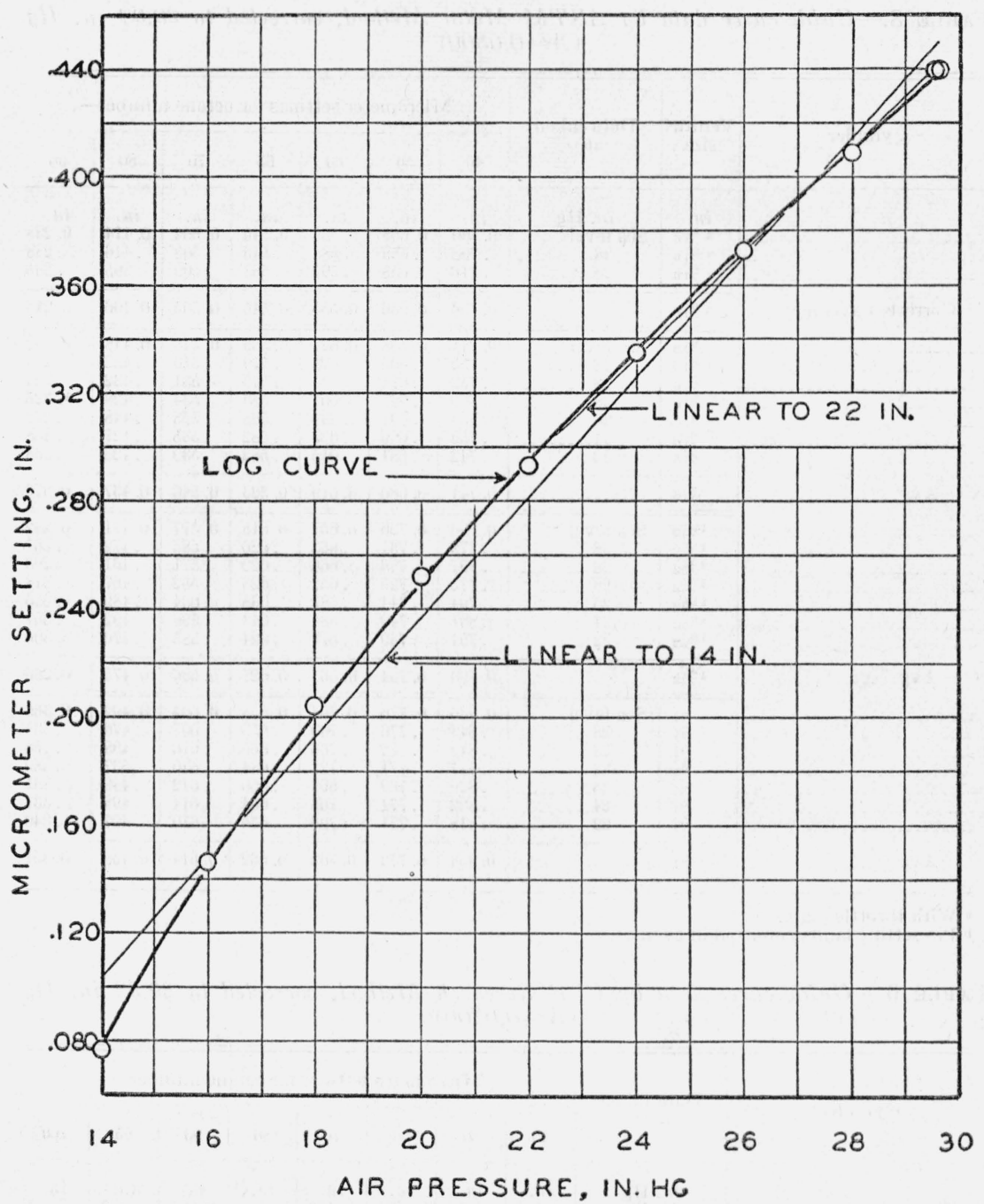

FIGURE 2.-Micrometer setting for standard knock intensity by CFR Research Method.

A linear equation fits the data well over the range from sea level to $22 \mathrm{in}$. Hg, but a logarithmic equation is required when the range is extended to $14 \mathrm{in}$. Hg (approximately $20,000 \mathrm{ft}$ ).

In table 10 this has been carried a step further. By subtracting a suitable constant from the average micrometer settings found for each venturi the guide curves can be superposed, apparently within experimental error. This means that change of venturi size has an effect analogous to change of air pressure. 
724 Journal of Research of the National Bureau of Standards

TABLE 8.-Guide-curve data by ASTM Motor Method, corrected to $29.92 \mathrm{in}$. Hg $(A=0.0300)$

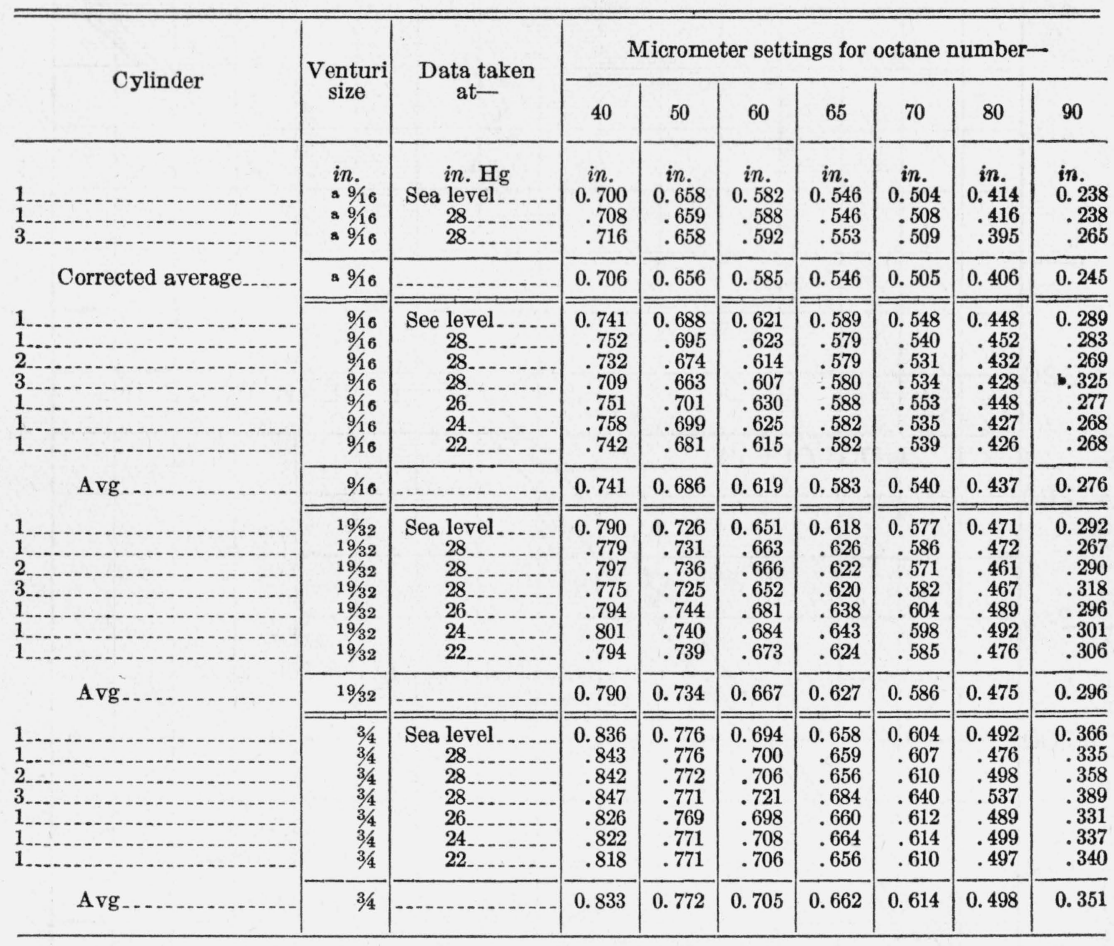

s With throttle plate.

b Pin setting faulty, omitted in average.

TABLE 9.-Guide-curve data by CFR Research Method, corrected to $29.92 \mathrm{in}$. $\mathrm{Hg}$ $(A=0.0200)$

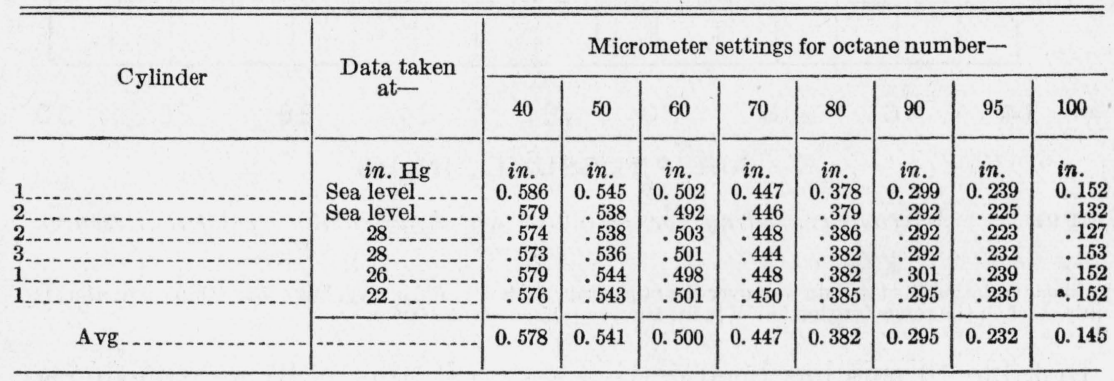

* Estimated. 
TABLE 10.-Guide curves corrected to common basis-ASTM Motor Method

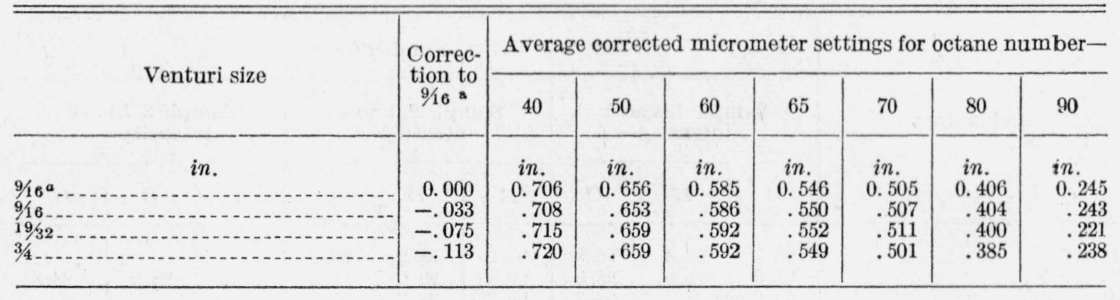

- With throttle plate.

\section{GUIDE CURVES}

As the altitude-chamber data by the ASTM Motor Method above 90 octane number were unsatisfactory, cooperative tests were carried out in January 1942. These tests were designed to determine the best compression ratio for knock rating at 100 octane number by this method. From previous work, it appeared that a value of compression ratio between 8 and 9 would be suitable when using the $\% 16$-in. venturi without the throttle plate. Each of the 14 laboratories cooperating in these tests was asked to set the bouncing pin to give the standard knockmeter reading (approximately midscale) at the knock intensity developed by 100-octane-number fuel at $8.0 \mathrm{com}$ pression ratio (corrected for air pressure by eq 6) and rate each of three fuels, two of which were very sensitive. The cooperating laboratories were further asked to repeat this procedure with the bouncing pin set on 100-octane-number fuel at 8.5 and at $9.0 \mathrm{com}$ pression ratios. The three knock intensities were designated $A, B$, and $C$, respectively. In reporting, the laboratories were asked to comment on the relative ease of rating and on bouncing-pin behavior at the three knock intensities.

The results of these tests are shown in table 11 . It will be seen that there was a slight increase in octane number and in knockmeter sensitivity (deflection per octane unit), and a decrease in the average standard deviation at the higher knock intensities. In commenting on relative ease of rating, most laboratories expressed a preference for intensity $B$, a few for $A$, and none for $C$. Some had experienced difficulties in rating at intensity $C$, and a few considered $A$ too low.

In approving the tests, the CFR Motor Fuels Division recommended that the guide curve be located within the compression-ratio range 8.2 to 8.5 at 100 octane number, preferably near the latter figure, and that the guide curve depart as little as possible from the former figure of 7.1 compression ratio at 90 octane number $(\% / 16$-in. venturi with throttle plate). 
TABLE 11.-Knock ratings of special fuels

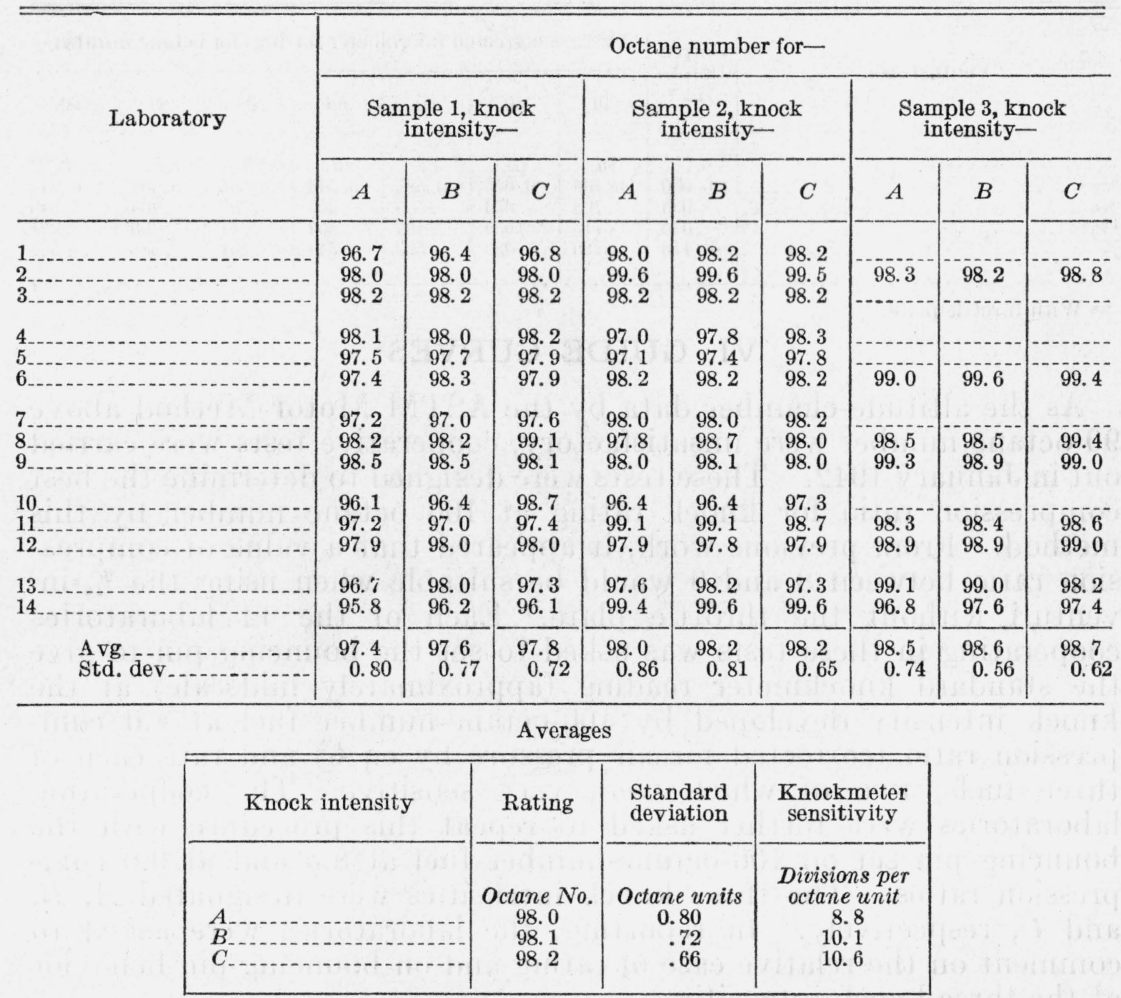

In order to utilize most fully the available data, and to give complete continuity to the guide tables, equations were developed to represent the data, and successive points of the tables were calculated therefrom. In the equations given below:

$$
\begin{aligned}
& y=\text { micrometer setting, in., } \\
& x=\text { octane number, } \\
& B=\text { barometric pressure, in. Hg. }
\end{aligned}
$$

For the ASTM Motor Method at 29.92 in. $\mathrm{Hg}$, using the $9 / 16$-in. venturi without the throttle plate,

$$
y_{0}=0.9169-0.0_{2} 5330 x+0.0_{4} 5075 x^{2}-0.0_{6} 6667 x^{3}-0.0_{8} 1250 x^{4} .
$$

For the other two venturis at standard air pressure, the micrometer settings are

$$
\begin{aligned}
19 / 2 \text {-in. venturi } & y_{1}=y_{0}+0.042, \\
3 / 4 \text {-in. venturi } & y_{2}=y_{0}+0.080 .
\end{aligned}
$$

For air pressures other than $29.92 \mathrm{in} . \mathrm{Hg}$, but above $22 \mathrm{in} . \mathrm{Hg}$, the micrometer setting is found from the relation

$$
y_{B}=y_{29 \cdot 92}-0.03(29.92-B) \text {. }
$$


For the CFR Research Method, in which only the 9/16-in. venturi without throttle plate is used, the relation between micrometer setting and octane number at a barometric pressure of $29.92 \mathrm{in} . \mathrm{Hg}$ is

$y_{29 \cdot 92}=0.6805-0.0_{2} 19857 x-0.0_{6} 44474 x^{3}+0.0_{10} 57168 x^{5}-0.0_{14} 45794 x^{7}(7)$

For other air pressures above $22 \mathrm{in} . \mathrm{Hg}$,

$$
y_{B}=y_{29 \cdot 92}-0.02(29.92-B) \text {. }
$$

Tabular values of eq 3 and 7 for the ASTM Motor and the CFR Research Methods for octane numbers from 40 to 100 at standard air pressures are given in table 12, p. 731.

In approving the new guide tables, the CFR Motor Fuels Division has recommended elimination of the throttle plate, and the use of only the following venturis for the ASTM Motor Method:

\begin{tabular}{|c|c|}
\hline Altitude & $\begin{array}{c}\text { Venturi } \\
\text { size }\end{array}$ \\
\hline $\begin{array}{r}\text { ft. } \\
0 \text { to } 1,600 \\
1,600 \text { to } 3,300 \\
\text { Over } 3,300\end{array}$ & $\begin{array}{l}i n . \\
9 / 16 \\
19 / 32 \\
3 / 4\end{array}$ \\
\hline
\end{tabular}

The guide tables embodying air pressure corrections derived from eq 3 and 6 for the ASTM Motor Method and eq 7 and 8 for the CFR Research Method are given in tables 13 to 16.

As developed, the ASTM Motor Method guide curve passes through 8.50 compression ratio at 100 octane number $(\% / 16$-in. venturi, no throttle plate) and 7.02 compression ratio instead of 7.10 at 90 octane number ( $\% 16$-in. venturi with throttle plate). This change in the compression ratio for standard knock intensity at 90 octane number, and the change from the former value of 6.70 to 6.65 compression ratio at 90 octane number by the CFR Research Method, can be ascribed almost entirely to the (average) difference in clearance volume resulting from the introduction of the tilt method of calibrating the micrometer zero (used in these tests), as compared with the former method, in which the clearance volume was measured with the engine level, which resulted in slight entrapment of air.

\section{EFFECT OF ALTITUDE ON OCTANE-NUMBER REQUIREMENT}

The octane-number requirement of an engine is the octane number of the fuel which will cause knock of a specified intensity when used in the engine at the throttle opening giving maximum knock. The requirement varies with engine and atmospheric conditions. Although engine conditions - such as speed, spark advance, coolant temperature, and amount of carbon deposit- can be regulated, no direct control of air pressure, temperature, or humidity can be had in road tests, or in service operation. Of these latter, air pressure can cause the greatest variation in octane-number requirement. Earlier road tests 
$[11,12]$ indicated a reduction in octane-number requirement averaging 3 octane units per $1,000 \mathrm{ft}$ increase of altitude.

Accurate information on the effect of altitude on octane-number requirement of CFR engines is afforded by the data of the altitudechamber tests. The relation between air pressure, $B$, and octanenumber requirement, $x$, can be found for the ASTM Motor Method engine from eq 3 and 6 , as follows. From eq 3 ,

$$
d y / d x=-0.0_{2} 5330+0.0_{3} 1015 x-0.0_{5} 2000 x^{2}-0.0_{8} 5000 x^{3} \text {. }
$$

From eq 6,

Hence

$$
d y / d B=-0.03
$$

and

$$
d B / d x=+0.1777-0.0_{2} 3383 x+0.0_{4} 6667 x^{2}+0.0_{6} 1667 x^{3},
$$

$$
B=A+0.1777 x-0.0_{2} 1692 x^{2}+0.0_{4} 2222 x^{3}+0.0_{7} 417 x^{4} .
$$

Similarly, from eq 7 and 8, for the CFR Research Method engine,

$$
B=A+0.09928 x+0.0_{4} 22237 x^{3}-0.0_{8} 28584 x^{5}+0.0_{12} 22897 x^{7} \text {. }
$$

The integration constants $A$ can be evaluated from any known pair of values of $B$ and $x$. To illustrate the variation of octane-number requirement with altitude for different values of the requirement at sea level, figures 3 and 4 have been calculated from eq 12 and 13 . The equation for each curve on these figures has been found by evaluating $A$ (eq 12 or 13) for a value of $x$ which is an integer at $B=29.92$.

A comparison of figures 3 and 4 shows that they do not differ to any great degree-in fact, not much more than could result from experimental errors - contrary to what might possibly have been expected from the large difference in eq 6 and 8 . The road-test data of MacCoull, Hollister, and Crone [12] are generally in somewhat better agreement with figure 3 than with figure 4 , if due allowance is made for the probable differences of humidity in their tests at different natural altitudes. It appears possible that the variation of octane-number requirement with altitude is nearly independent of the engine used. In any case, estimates of this variation for automobiles made from figure 3 will be correct within the experimental error of road testing.

\section{CONCLUSIONS}

The conclusions drawn from the tests reported herein and holding over the ranges covered by these tests are as follows:

1. The effect of altitude on knock ratings can be obviated by operating at constant knock intensity.

2. The micrometer setting giving constant knock intensity is a linear function of air pressure, the derivative of this function being invariant with octane number and being $0.030 \mathrm{in}$. per in. $\mathrm{Hg}$ for the ASTM Motor Method and 0.020 in. per in. Hg for the CFR Research Method.

3. The effect on knock intensity of a change in volumetric efficiency caused by change of venturi size or other restriction can be compensated by a change of micrometer setting, the amount of this change being the same at all altitudes and all octane numbers.

4. For both test methods, the micrometer setting for standard knock intensity is a direct polynomial function of the octane number, within experimental error. 
5. The functions relating octane-number requirement of CFR engines to altitude are derivable from the guide curves, and appear to be of general applicability.

\section{ALTITUDE, THOUSANDS OF FEET}
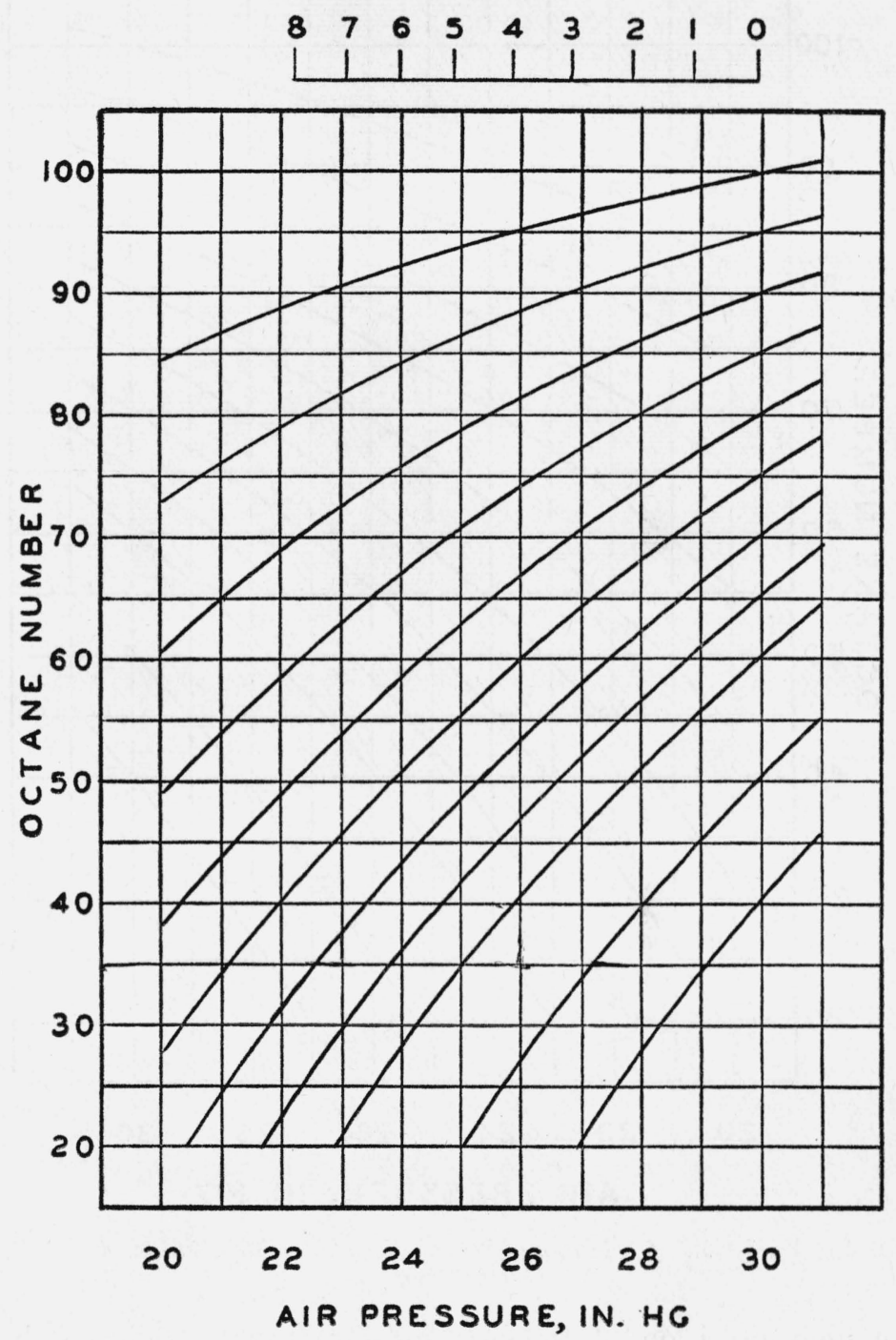

FiguRE 3.-Variation of octane-number requirement with altitude, ASTM Motor Method engine. 
ALTITUDE, THOUSANDS OF FEET

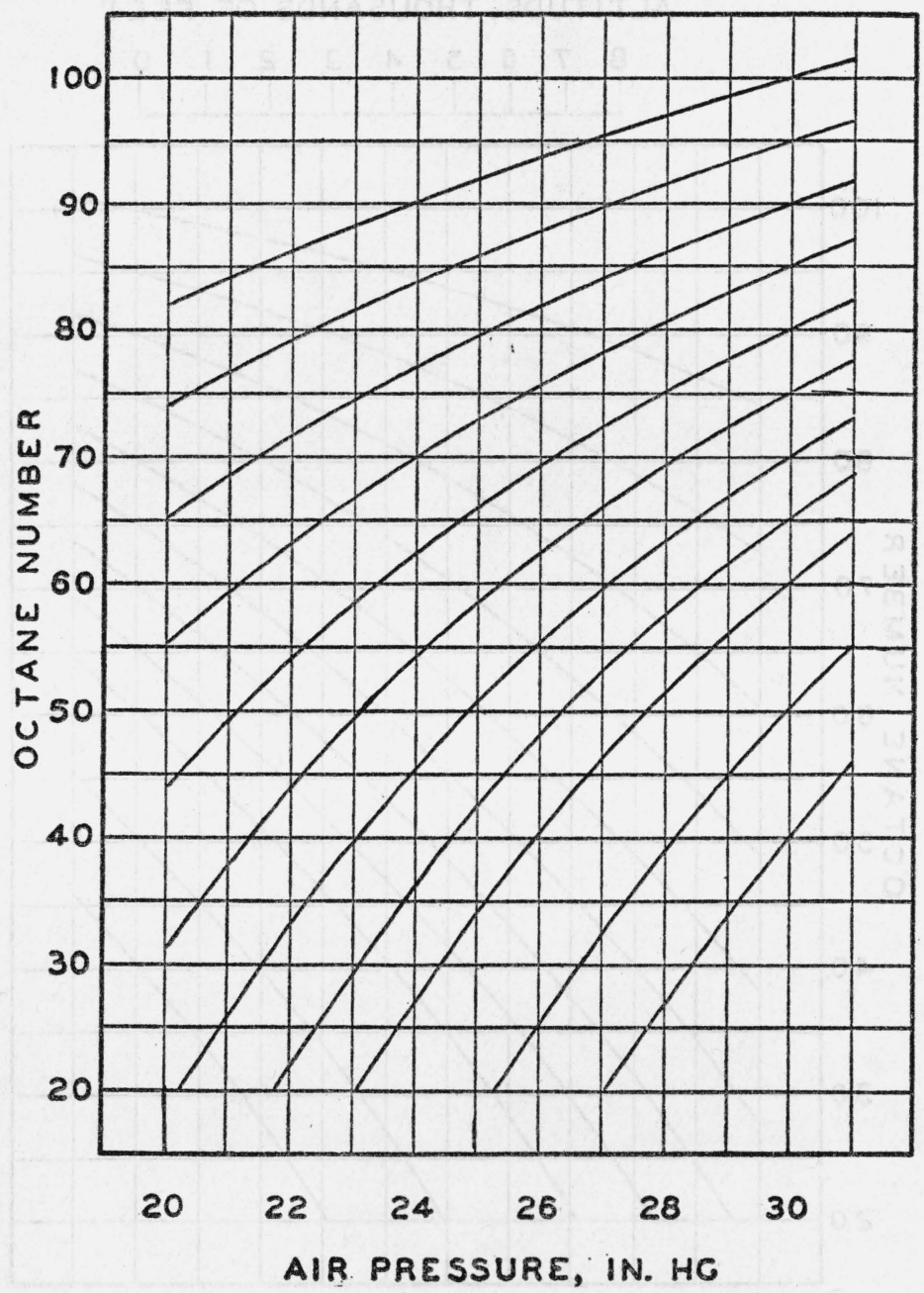

FIGURE 4.-Variation of octane-number requirement with altitude, CFR Research Method engine.

The high precision of the altitude-chamber test data, which so greatly facilitated this analysis, amply bespeaks the technical skill and thoroughness of the cooperating participants: B. A. Kulason, of The Texas Co.; J. L. Philips and H. R. Jacobus, of the Standard Oil Development Co.; W. S. Mount and G. MacDonald, of the Socony-Vacuum Oil Co., Inc.; B. R. Siegel, of the Sinclair Refining Co.; and C. H. Walstrom and A. R. Pierce, of the National Bureau of Standards, whose careful work is gratefully acknowledged. 


\section{REFERENCES}

[1] W. M. Holaday and G. T. Moore, Effect of Altitude on Octane Number Determination, presented at SAE Annual Meeting, January 1937.

[2] Standard engine for fuel tests, SAE Journal 24, No. 2, 212 (1929).

[3] H. L. Horning, Standardization of antiknock testing, Proc. API 11 (III), 32 (Jan. 2, 1930).

[4] H. L. Horning, The Cooperative Fuel Research Committee engine, SAE Transactions 26, 436 (1931).

[5] T. A. Boyd, The Cooperative Fuel Research apparatus and method for knock testing, Proc. API 12 (III), 46 (December 1931).

[6] CFR Research Method of test for knock characteristics of motor fuels, SAE Transactions 34, 277 (1939).

[7] 1941 Supplement to ASTM Standards, pt. 3, p. 381 (Am. Soc. for Testing Materials, 260 S. Broad St., Philadelphia, Pa.).

[8] H. K. Cummings and A. E. Garlock, Altitude laboratory testing of aircraft engines, Aeron. Eng. 4, No. 2, 53-60 (1932); Transactions ASME 54 (1932).

[9] Donald B. Brooks and Robetta B. Cleaton, The precision of knock rating, 1936-1938, SAE Transactions 34, 449 (1939).

10] Donald B. Brooks, Correlation of Altitude Chamber Data, (unpublished report to CFR Motor Fuels Division, June 1941).

11] CFR Motor Survey Report, 1937 (unpublished) and unpublished data of the National Bureau of Standards.

12] Neil MacCoull, K. L. Hollister, and R. C. Crone, Effect of altitude on antiknock requirements of cars, Proc. API 18 (III), 137 (November 1937).

Washington, February 20, 1942.

TABLE 12.-Micrometer setting for standard knock intensity

[9/16-in. venturi-barometric pressure of 29.92 in. $\mathrm{Hg}$ ]

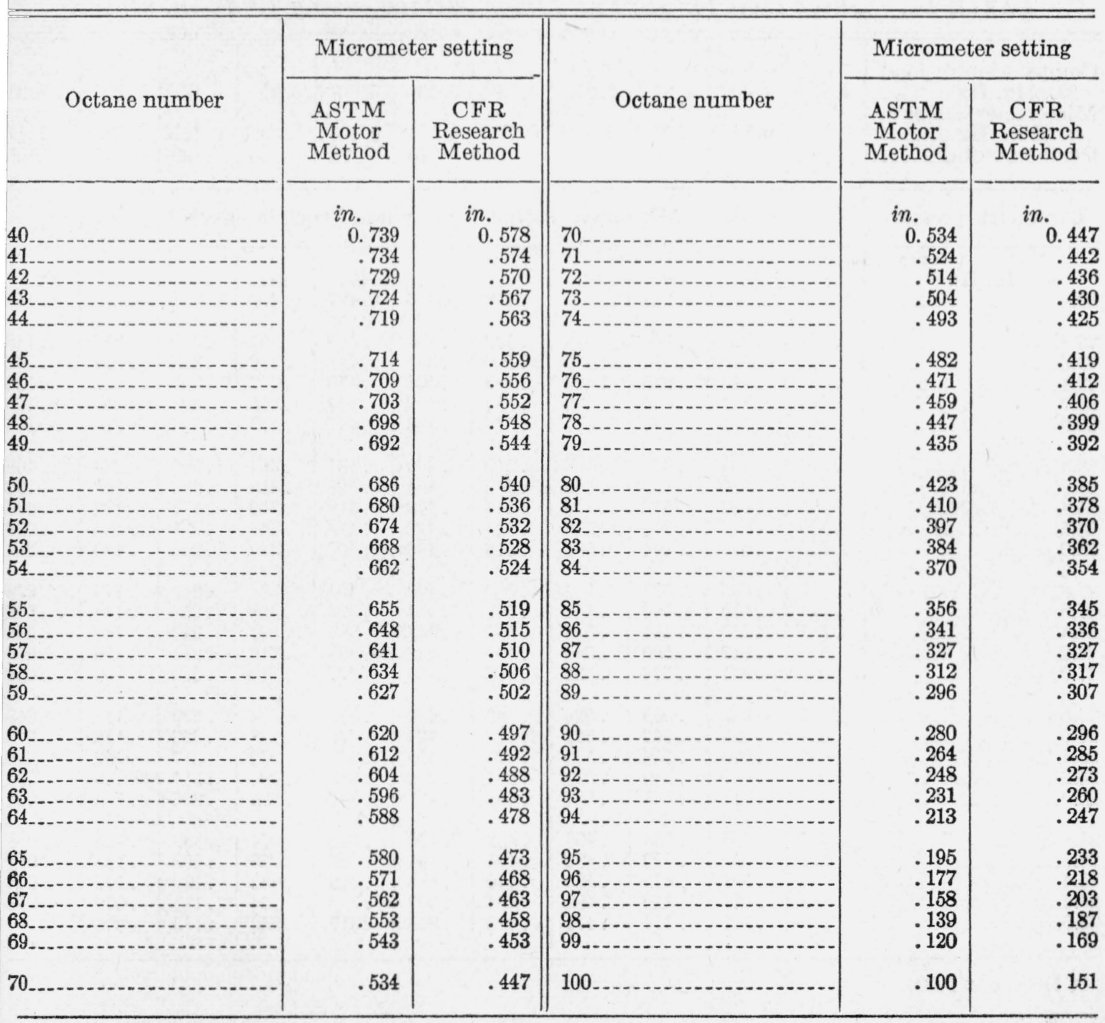




\section{Journal of Research of the National Bureau of Standards}

TABLE 13.-Guide table for ASTM Motor Method, using 9/16-in. venturi

\begin{tabular}{|c|c|c|c|c|c|c|c|c|c|c|c|}
\hline $\begin{array}{l}\text { Compression ratio at } \\
29.92 \text { in. Hg } \\
\text { Micrometer setting at } \\
29.92 \text { in. Hg } \\
\text { Octane number }\end{array}$ & $\begin{array}{c}4.63 \\
0.7391 \\
40\end{array}$ & $\begin{array}{l}4.79 \\
0.6862 \\
50\end{array}$ & $\begin{array}{c}5.02 \\
0.6196 \\
60\end{array}$ & $\begin{array}{l}5.17 \\
0.5795 \\
65\end{array}$ & $\begin{array}{l}5.35 \\
0.5338 \\
70\end{array}$ & $\begin{array}{c}5.58 \\
0.4818 \\
75\end{array}$ & $\begin{array}{l}5.88 \\
0.4228 \\
80\end{array}$ & $\begin{array}{l}6.26 \\
0.3559 \\
85\end{array}$ & $\begin{array}{c}6.77 \\
0.2803 \\
90\end{array}$ & $\begin{array}{c}7.47 \\
0.1952 \\
95\end{array}$ & $\begin{array}{r}8.5 \\
0.099 \\
10\end{array}$ \\
\hline Barome & \multicolumn{11}{|c|}{ Micrometer setting for standard knock intensity } \\
\hline $31.0 \quad$ in. & in. & in. & $\begin{array}{l}i n . \\
0.652\end{array}$ & ${ }_{0.612}^{i n}$ & in. & in & $\begin{array}{l}i n . \\
0.455\end{array}$ & $\begin{array}{l}\text { in. } \\
0.388\end{array}$ & in. & $\begin{array}{c}\text { in. } \\
0.228\end{array}$ & $\begin{array}{l}\text { in } \\
0.13\end{array}$ \\
\hline 30.0 & $\begin{array}{l}.765 \\
.759 \\
.753 \\
.747 \\
.741\end{array}$ & $\begin{array}{l}.713 \\
.707 \\
.701 \\
.695 \\
.689\end{array}$ & $\begin{array}{l}.646 \\
.640 \\
.634 \\
.628 \\
.622\end{array}$ & $\begin{array}{l}.606 \\
.600 \\
.594 \\
.588 \\
.582\end{array}$ & $\begin{array}{l}.560 \\
.554 \\
.548 \\
.542 \\
.536\end{array}$ & $\begin{array}{l}.508 \\
.502 \\
.496 \\
.490 \\
.484\end{array}$ & $\begin{array}{l}.449 \\
.443 \\
.437 \\
.431 \\
.425\end{array}$ & $\begin{array}{l}.382 \\
.376 \\
.370 \\
.364 \\
.358\end{array}$ & $\begin{array}{l}.307 \\
.301 \\
.295 \\
.289 \\
.283\end{array}$ & $\begin{array}{l}.222 \\
.216 \\
.210 \\
.204 \\
.198\end{array}$ & $\begin{array}{l}.12 \\
.12 \\
.11 \\
.10 \\
.10\end{array}$ \\
\hline $\begin{array}{l}29.4 \\
29.2 \\
29.0\end{array}$ & $\begin{array}{l}.735 \\
.729 \\
.723 \\
.717 \\
.711\end{array}$ & $\begin{array}{l}.683 \\
.677 \\
.671 \\
.665 \\
.659\end{array}$ & $\begin{array}{l}.616 \\
.610 \\
.604 \\
.598 \\
.592\end{array}$ & $\begin{array}{l}.576 \\
.570 \\
.564 \\
.558 \\
.552\end{array}$ & $\begin{array}{l}.530 \\
.524 \\
.518 \\
.512 \\
.506\end{array}$ & $\begin{array}{l}.478 \\
.472 \\
.466 \\
.460 \\
.454\end{array}$ & $\begin{array}{r}.419 \\
.413 \\
.407 \\
.401 \\
.395\end{array}$ & $\begin{array}{l}.352 \\
.346 \\
.340 \\
.334 \\
.328\end{array}$ & $\begin{array}{l}.277 \\
.271 \\
.265 \\
.259 \\
.253\end{array}$ & $\begin{array}{l}.192 \\
.186 \\
.180 \\
.174 \\
.168\end{array}$ & $\begin{array}{l}.09 \\
.09 \\
.08 \\
.07 \\
.07\end{array}$ \\
\hline $\begin{array}{l}28 \\
28 \\
28\end{array}$ & $\begin{array}{l}.705 \\
.699 \\
.693 \\
.687 \\
.681\end{array}$ & $\begin{array}{l}.653 \\
.647 \\
.641 \\
.635 \\
.629\end{array}$ & $\begin{array}{l}.586 \\
.580 \\
.574 \\
.568 \\
.562\end{array}$ & $\begin{array}{l}.546 \\
.540 \\
.534 \\
.528 \\
.522\end{array}$ & $\begin{array}{l}.500 \\
.494 \\
.488 \\
.482 \\
.476\end{array}$ & $\begin{array}{l}.448 \\
.442 \\
.436 \\
.430 \\
.424\end{array}$ & $\begin{array}{l}.389 \\
.383 \\
.377 \\
.371 \\
.365\end{array}$ & $\begin{array}{l}.322 \\
.316 \\
.310 \\
.304 \\
.298\end{array}$ & $\begin{array}{l}.247 \\
.241 \\
.235 \\
.229 \\
.223\end{array}$ & $\begin{array}{l}.162 \\
.156 \\
.150 \\
.144 \\
.138\end{array}$ & $\begin{array}{l}.06 \\
.06 \\
.05 \\
.04 \\
.04\end{array}$ \\
\hline $\begin{array}{l}27.8 \\
27.6 \\
27.4 \\
27.2 \\
27.0\end{array}$ & $\begin{array}{l}.675 \\
.669 \\
.663 \\
.657 \\
.651\end{array}$ & $\begin{array}{l}.623 \\
.617 \\
.611 \\
.605 \\
.599\end{array}$ & $\begin{array}{l}.556 \\
.550 \\
.544 \\
.538 \\
.532\end{array}$ & $\begin{array}{l}.516 \\
.510 \\
.504 \\
.498 \\
.492\end{array}$ & $\begin{array}{l}.470 \\
.464 \\
.458 \\
.452 \\
.446\end{array}$ & $\begin{array}{l}.418 \\
.412 \\
.406 \\
.400 \\
.394\end{array}$ & $\begin{array}{l}.359 \\
.353 \\
.347 \\
.341 \\
.335\end{array}$ & $\begin{array}{l}.292 \\
.286 \\
.280 \\
.274 \\
.268\end{array}$ & $\begin{array}{l}.217 \\
.211 \\
.205 \\
.199 \\
.193\end{array}$ & $\begin{array}{l}.132 \\
.126 \\
.120 \\
.114 \\
.108\end{array}$ & $\begin{array}{l}.03 \\
.03 \\
.02 \\
.01 \\
.01\end{array}$ \\
\hline
\end{tabular}

TABLE 14.-Guide table for ASTM Motor Method, using 19/32-in. venturi

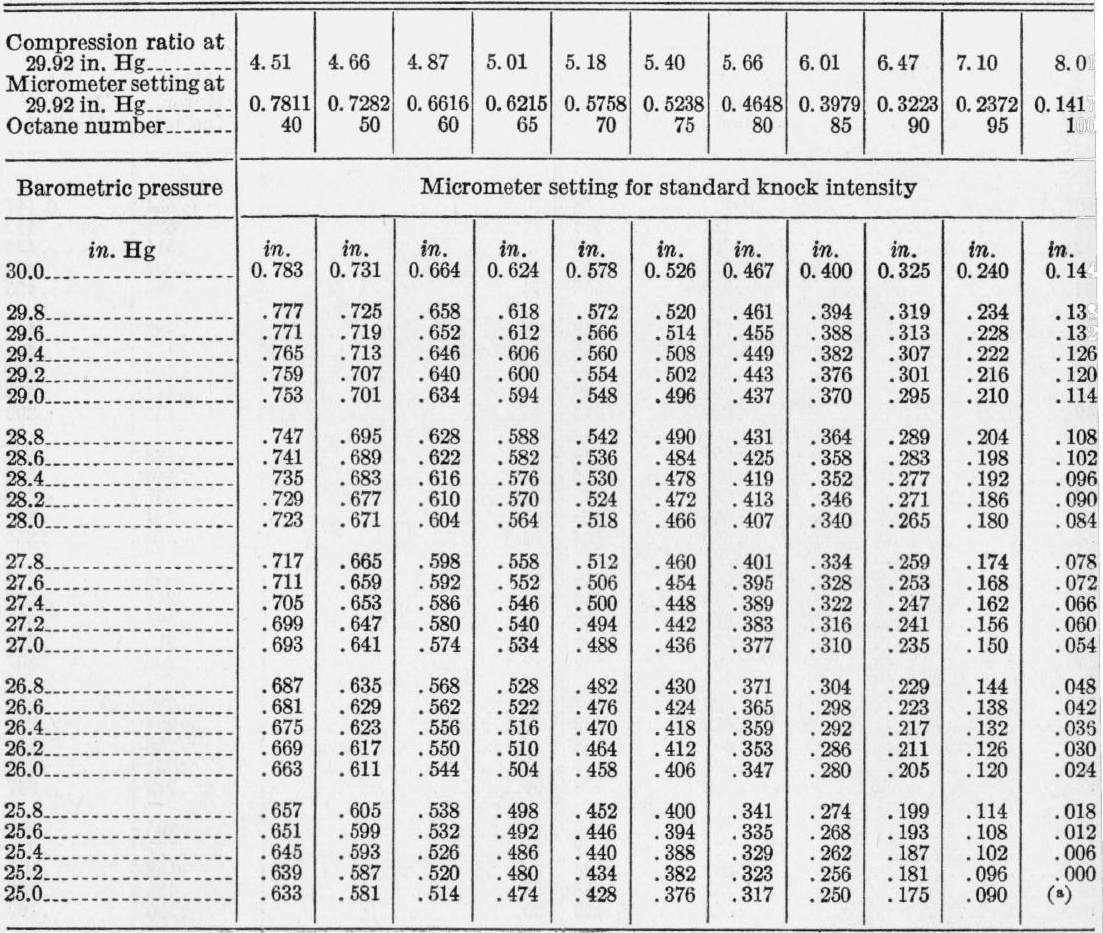

a Less than 0.000 . 
TABLE 15.-Guide table for ASTM Motor Method, using 3/4-in. venturi

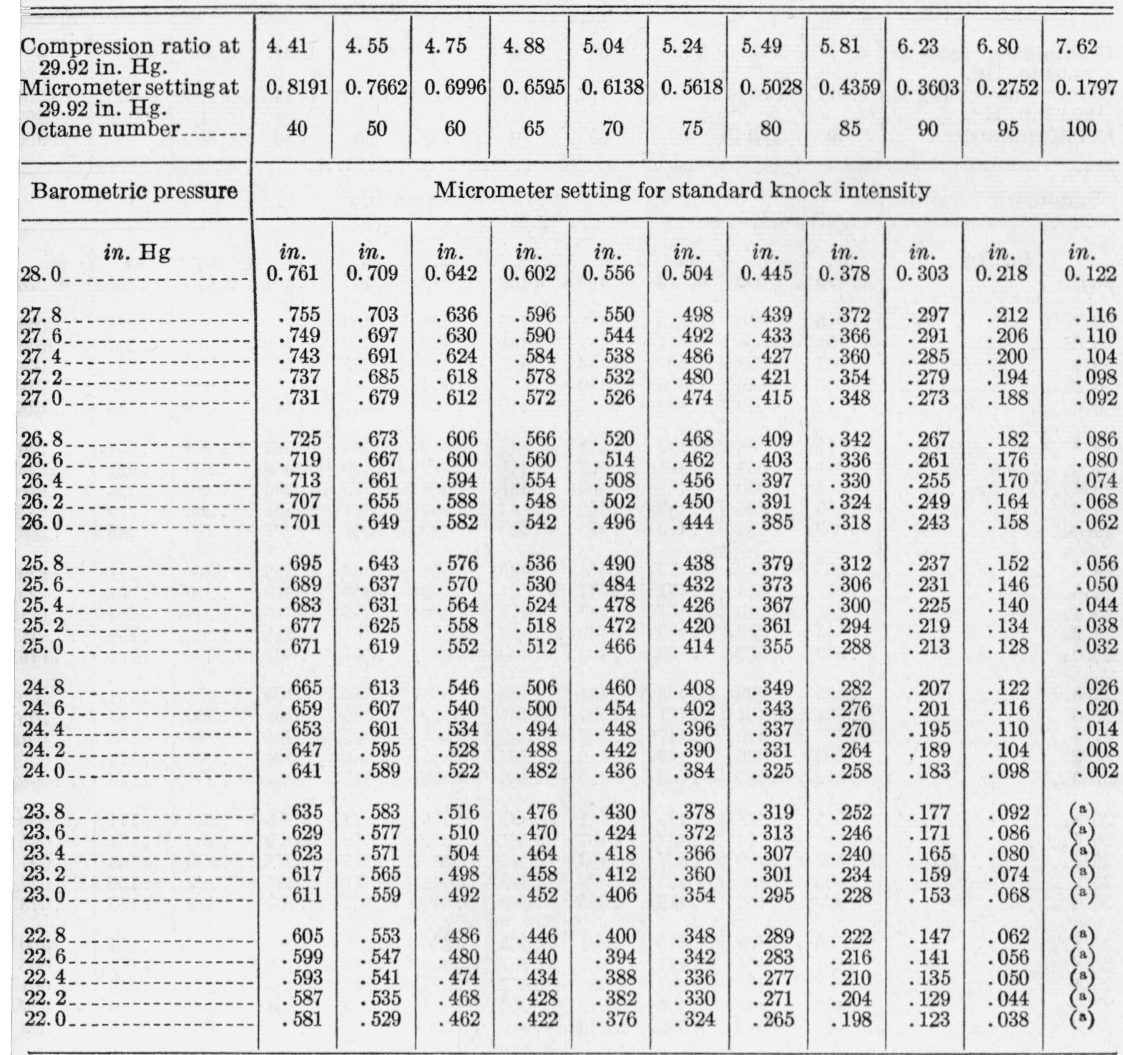

a Less than 0.000 . 
734 Journal of Research of the National Bureau of Standards

TABLE 16.-Guide table for 1942 CFR Research Method, using $\% 16$-in. venturi

\begin{tabular}{|c|c|c|c|c|c|c|c|c|c|c|c|}
\hline Compr & 5.18 & 5.33 & 5. 51 & 5. 62 & 5.75 & 5.90 & 6.08 & 6. 32 & 6.65 & 7.14 & 7.91 \\
\hline Micrometer setting at & 0.5777 & 0.5399 & 0.4970 & 0.4732 & 0.4474 & 0.4186 & 0.3852 & 0.3455 & 0.2962 & 0.2332 & 0.151 \\
\hline Octane numb & 40 & 50 & 60 & 65 & 70 & 75 & 80 & 85 & 90 & 95 & 100 \\
\hline Barometric pressure & \multicolumn{11}{|c|}{ Micrometer setting } \\
\hline $31.0 \ldots$ & $\begin{array}{c}\text { in. } \\
0.599\end{array}$ & $\begin{array}{l}\text { in. } \\
0.562\end{array}$ & $\begin{array}{c}\text { in. } \\
0.519\end{array}$ & ${ }_{0.495}^{i n}$ & $\begin{array}{c}\text { in. } \\
0.469\end{array}$ & $\begin{array}{l}\text { in. } \\
0.440\end{array}$ & $\stackrel{i n .}{i n}$ & $\begin{array}{c}\text { in. } \\
0.367\end{array}$ & $\begin{array}{l}\text { in. } \\
0.318\end{array}$ & $\begin{array}{l}\text { in. } \\
0.255\end{array}$ & $\begin{array}{l}\text { in. } \\
0.173\end{array}$ \\
\hline 30.8 & .595 & .558 & .515 & .491 & .465 & .436 & .403 & .363 & .314 & .251 & .16 \\
\hline 0 & .591 & .554 & .511 & .487 & .461 & .432 & .399 & .359 & .310 & .247 & .165 \\
\hline 30 & .587 & .550 & .507 & .483 & .457 & .428 & .395 & .355 & .306 & .243 & . 161 \\
\hline 30 & .583 & .546 & .503 & .479 & .453 & .424 & .391 & .351 & .302 & .239 & .157 \\
\hline 30.0 - & .579 & & .499 & .475 & .449 & .420 & .387 & .347 & .298 & .235 & .153 \\
\hline 29.8 & .575 & .538 & .495 & .471 & .445 & .416 & .383 & .343 & .294 & .231 & . 149 \\
\hline & .571 & .534 & .491 & .467 & .441 & .412 & .379 & .339 & .290 & .227 & .145 \\
\hline 2 & .567 & .530 & .487 & .463 & .437 & .408 & .375 & .335 & .286 & .223 & .141 \\
\hline $\begin{array}{l}29 \\
2 !\end{array}$ & $\begin{array}{l}.563 \\
.559\end{array}$ & $\begin{array}{l}.526 \\
522\end{array}$ & $\begin{array}{r}.483 \\
-479\end{array}$ & $\begin{array}{r}.459 \\
455\end{array}$ & .433 & .404 & .371 & .331 & .282 & .219 & .137 \\
\hline & & & & & .429 & .400 & .367 & .327 & .278 & .215 & .135 \\
\hline 28.8 & .555 & .518 & .475 & .451 & .425 & .396 & .363 & .323 & .274 & .211 & .129 \\
\hline & .551 & .514 & .471 & .447 & .421 & .392 & .359 & .319 & .270 & .207 & .125 \\
\hline 20 & .547 & .510 & .467 & .443 & .417 & .388 & .355 & .315 & .266 & .203 & .121 \\
\hline 28. & .543 & .506 & .463 & .439 & .413 & .384 & .351 & .311 & .262 & .199 & .117 \\
\hline 28. & .539 & .502 & .459 & .435 & .409 & .380 & .347 & .307 & .258 & .195 & .113 \\
\hline 27.8 & .535 & .498 & .455 & .431 & .405 & .376 & .343 & .303 & .254 & .191 & .109 \\
\hline & .531 & .494 & .451 & .427 & .401 & .372 & .339 & .299 & .250 & .187 & .105 \\
\hline 27 & .527 & .490 & .447 & .423 & .397 & .368 & .335 & .295 & .246 & .183 & .101 \\
\hline 27. & .523 & .486 & .443 & .419 & .393 & .364 & .331 & .291 & .242 & .179 & .097 \\
\hline 27.0 & .519 & .482 & .439 & .415 & .389 & .360 & .327 & .287 & .238 & .175 & .093 \\
\hline 26.8 & .515 & .478 & .435 & .411 & .385 & .356 & .323 & .283 & .234 & .171 & .089 \\
\hline & .511 & .474 & .431 & .407 & .381 & .352 & .319 & .279 & .230 & .167 & .085 \\
\hline 26 & .507 & .470 & .427 & .403 & .377 & .348 & .315 & .275 & .226 & .163 & .081 \\
\hline & .503 & .466 & 423 & .399 & .373 & .344 & .311 & .271 & .222 & .159 & .077 \\
\hline 26 . & .499 & .462 & .419 & .395 & .369 & .340 & .307 & .267 & .218 & .155 & .073 \\
\hline 25.8 & . 495 & .458 & .415 & .391 & .365 & . 336 & .303 & .263 & .214 & .151 & .069 \\
\hline & .491 & .454 & .411 & .387 & .361 & .332 & .299 & .259 & .210 & .147 & .065 \\
\hline & .487 & .450 & .407 & .383 & .357 & .328 & .295 & .255 & .206 & .143 & .061 \\
\hline 25 & .483 & .446 & .403 & .379 & 353 & .324 & .291 & .251 & .202 & .139 & .057 \\
\hline & .479 & .442 & .399 & .375 & .349 & .320 & .287 & .247 & .198 & .135 & .053 \\
\hline 24.8 & .475 & .438 & .395 & .371 & .345 & .316 & .283 & .243 & .194 & .131 & .049 \\
\hline & .471 & .434 & .391 & .367 & .341 & 3 & .279 & .239 & .190 & .127 & .045 \\
\hline & .467 & .430 & .387 & .363 & .337 & .308 & .275 & .235 & .186 & .123 & .041 \\
\hline 24 & .463 & .426 & .383 & .359 & .333 & .304 & .271 & .231 & .182 & .119 & .037 \\
\hline & .459 & .422 & .379 & .355 & .329 & .300 & .267 & .227 & .178 & .115 & .033 \\
\hline 23.8 & .455 & .418 & .375 & .351 & .325 & .296 & .263 & .223 & .174 & .111 & .029 \\
\hline & .451 & .414 & .371 & .347 & .321 & .29 & .25 & .219 & .170 & .107 & .025 \\
\hline & .447 & .410 & .367 & .343 & .317 & .2 & .255 & .215 & .166 & .103 & .021 \\
\hline & .443 & .406 & .363 & .339 & .313 & .284 & .251 & .211 & .162 & .099 & .017 \\
\hline 23 & .439 & .402 & .359 & .335 & .309 & .280 & .247 & .207 & .158 & .095 & .013 \\
\hline 22. & .435 & .398 & .355 & .331 & .305 & .276 & .243 & .203 & .154 & .091 & .009 \\
\hline & .431 & .394 & .351 & .327 & .301 & .272 & .23 & .199 & .150 & .087 & .005 \\
\hline & .427 & .390 & .347 & .323 & .297 & .268 & .235 & .195 & .146 & .083 & .001 \\
\hline & .423 & .386 & .343 & .319 & .293 & .264 & .231 & .191 & .142 & .079 & (a) \\
\hline 22.0 & .419 & .382 & .339 & .315 & .289 & .260 & .227 & .187 & .138 & .075 & (a) 8 \\
\hline
\end{tabular}

s Less than 0.000 . 